\title{
Role of Prostanoids in the Regulation of Cerebral Blood Flow During Normoxia and Hypoxia in the Fetal Sheep
}

\author{
NAOKO NISHIDA, ARLIN B. BLOOD, CHRISTIAN J. HUNTER, SHANNON BRAGG, JAMES WILLIAMS, \\ WILLIAM J. PEARCE, AND GORDON G. POWER
}

\begin{abstract}
Department of Obstetrics and Gynecology [N.N.], Nippon Medical School, Tokyo, Japan 13-8602, Center for Perinatal Biology [N.N., A.B.B., C.J.H., S.B., J.W., W.J.P., G.G.P.], Department of Pediatrics, Division of Neonatology [A.B.B.], School of Medicine, Loma Linda University, Loma Linda, California 92354
\end{abstract}

\begin{abstract}
The fetal cardiovascular responses to hypoxia include decreased peripheral blood flow and increased cerebral, cardiac, and adrenal blood flow. Prostanoids, metabolites of cyclooxygenase enzyme activity, have potent effects on vascular tone in both the adult and the fetus. To examine the role of prostanoids in the regulation of fetal cerebral blood flow (CBF) during acute hypoxic stress, eight near term fetal sheep were studied after infusing vehicle or diclofenac, a cyclooxygenase inhibitor, followed by a 30-min period of hypoxia (arterial $\mathrm{Po}_{2} 12$ Torr). In the control experiments, $\mathrm{CBF}$, measured continuously with laser Doppler flowmetry, increased to $148 \%$ of baseline values $(p<0.01)$ and cerebral vascular resistance decreased to $70 \%$ of baseline values after $30 \mathrm{~min}$ of hypoxic stress. During diclofenac infusion, hypoxia resulted in a CBF increase to only $129 \%$ of baseline, a significant attenuation $(p<0.05)$, accompanied by decreased plasma prostanoid concentrations. Increases in mean arterial blood pressure during hypoxia were also attenuated by diclofenac infusion. Flow and pressure responses were not accompanied by changes in cerebral vascular resistance. These results indicate that prostanoids indirectly modulate fetal $\mathrm{CBF}$ responses to hypoxia, but that their effects are mediated through modulation of systemic rather than cerebral vascular tone. (Pediatr Res 60: 524529, 2006)
\end{abstract}

$\mathrm{T}$ The fetus is often subjected to hypoxic insult during gestation and labor. In defense against hypoxic injury, mechanisms come into play that optimize the balance between oxygen delivery and consumption in vital organs such as the brain, heart, and adrenals. In the fetal brain, this is accomplished in part by an increase in CBF (1-3), a regulated reduction in oxidative metabolism (4-6), and an increase in anaerobic metabolism. This increase in CBF is accomplished in part by redistribution of blood flow during hypoxic stress resulting in increased blood flow to vital organs and decreased blood flow to peripheral organs (1). The redistribution of flow to these organs is the result of increased systemic arterial blood pressure and decreased local cerebral vascular resistance $(1,7)$. Previous work by our group and others has shown that both adenosine and nitric oxide are important mediators of this effect $(5,6)$. However, the changes in CBF and vascular

Received March 10, 2006; accepted June 12, 2006.

Correspondence: Gordon G. Power, M.D., Center for Perinatal Biology, Loma Linda University School of Medicine, Loma Linda, CA 92350; e-mail: gpower@1lu.edu.

The work was supported in part by National Institutes of Health grants HL6564941 (G.G.P.) and HL64867 (W.J.P.).

DOI: $10.1203 / 01 . p d r .0000242268 .99726 .53$ resistance during hypoxia cannot be completely attributed to these systems. The studies presented here focus on the role of prostanoids in mediating these changes in blood flow to the fetal brain during hypoxia.

Prostanoids, a subclass of eicosanoids that includes prostaglandins and thromboxanes, are found throughout biologic tissues and are important modulators of vascular tone. Prostanoids are synthesized by oxidation of free arachidonic acid, a reaction catalyzed by cyclooxygenase enzymes cyclooxygenase $1(\mathrm{COX}-1)$ and cyclooxygenase $2(\mathrm{COX}-2)$. In adult vascular tissues, COX-1 is a constitutive enzyme, whereas COX-2 is an inducible enzyme, both of which are involved in the production of precursors of the vasoconstrictor thromboxane [thromboxane $\mathrm{A}_{2}\left(\mathrm{TxA}_{2}\right)$ ], the vasodilator prostaglandin $\mathrm{I}_{2}\left(\mathrm{PGI}_{2}\right)$, and prostaglandin $\mathrm{E}_{2}\left(\mathrm{PGE}_{2}\right)$ and prostaglandin $\mathrm{F}_{2 \alpha}$ $\left(\mathrm{PGF}_{2 \alpha}\right)$, which can induce either vasoconstriction or vasodilation (8). The activity of both COX enzymes can be selectively antagonized by diclofenac (9).

Prostanoids play an important role in the regulation of basal CBF of adults (10-13), newborns (14-16), and fetuses $(17,18)$, although there is at least one report of no effect of COX inhibition in adults (19). Data regarding the role of prostanoids in the regulation of vascular responses to hypoxia are less clear, with some reports concluding they do play a role (20) and some concluding they do not $(15,21)$. In the fetus, although prostanoids have been suggested to play a role in the regulation of $\mathrm{CBF}$ responses to hypotension (22) and in metabolic responses to hypoxia $(17,23)$, we found no reports on the role of prostanoids in the regulation of fetal CBF responses to hypoxia.

In recent work, we have shown important roles for adenosine and nitric oxide in cerebral vasodilation during hypoxia in the near term fetal sheep $(2,5,6)$. A number of reports in adults and newborns suggests that a complex interaction exists between these modulators and prostanoids in the vascular response to hypoxia $(24,25)$. Therefore, we hypothesized that prostanoids would also be involved in mediating fetal CBF

Abbreviations: CBF, cerebral blood flow; COX 1, cyclooxygenase 1; COX

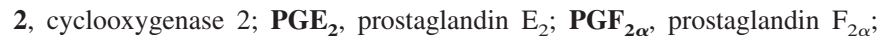
$\mathbf{P G I}_{2}$, prostaglandin $\mathrm{I}_{2} ; \mathbf{T x} \mathbf{A}_{2}$, thromboxane $\mathrm{A}_{2} ; \mathbf{T} \mathbf{x} \mathbf{B}_{2}$, thromboxane $\mathrm{B}_{2}$ 
responses to hypoxia. The present study was designed to test this hypothesis by examining the effects of i.v. infusion of diclofenac on the chronically instrumented fetal sheep before and during a period of acute hypoxic stress.

\section{METHODS}

Animal preparation. Animal protocols were approved by the Loma Linda University Animal Care Research Committee. Fourteen Western pregnant ewes obtained from Nebeker Ranch (Lancaster, CA) were used for the study. Ewes and fetuses were instrumented at 124 to $127 \mathrm{~d}$ of gestation. Anesthesia was induced with $0.5 \mathrm{~g}$ thiopental i.v. and maintained by inhalation of $1.5-2.5 \%$ halothane through a tracheal tube. A polyvinyl catheter was placed in the maternal femoral vein for administration of fluids and euthanasia solution at a termination of the experiments. Under aseptic conditions, through a midline abdominal incision, the uterus was incised and the fetal head and upper torso were exposed. Polyvinyl catheters were placed in brachial arteries bilaterally for arterial blood sampling and blood pressure measurement, in the right subclavian vein for drug administration, and in the amniotic fluid for pressure measurement and administration of antibiotics. A thermocouple was placed in a brachial artery for fetal temperature measurement. The fetal skull was exposed, and a polyvinyl catheter was inserted into the sagittal sinus for cerebral venous blood sampling. Bur holes $0.5 \mathrm{~mm}$ in diameter were made bilaterally $5 \mathrm{~mm}$ lateral to the sagittal sinus suture and 15 $\mathrm{mm}$ posterior to the coronal suture. A thermocouple was inserted in one bur hole for brain temperature measurement. A composite laser Doppler flow and tissue $\mathrm{PO}_{2}$ probe (Oxford Optronix, Oxford, UK) was inserted through the other into the parasagittal parietal lobe cortex to a depth $5 \mathrm{~mm}$ below the dura. The probe was then fixed to the skull with Germicidal Pink (Western Medical Supply, Arcadia, CA). The fetal skull was closed with tissue glue, the fetal upper torso was returned to the uterus and incisions sutured closed in layers. The catheters, probes, and thermocouple leads were passed to the ewe's flank and secured there in a nylon pouch. The ewe was given 900,000 U penicillin i.m. for $3 \mathrm{~d}$, and the fetus was given $40 \mathrm{mg}$ gentamicin and $500 \mathrm{mg}$ ampicillin in the amniotic fluid and $50 \mathrm{mg}$ cefotaxime i.v. once daily. Experiments were carried out beginning $4 \mathrm{~d}$ after the surgery with at least $48 \mathrm{~h}$ separating control and diclofenac protocols.

Experimental procedures. Two experiments were performed in random sequence in each fetal sheep. Each consisted of a 30-min baseline period, a 90-min i.v. infusion period, and a 30-min recovery period following the end of the infusion. In the control protocol, only the vehicle was given. Diclofenac was dissolved in a vehicle of $100 \mathrm{mM}$ sodium carbonate on the same day of the experiment. The drug was infused as a bolus of $1.33 \mathrm{mg} \mathrm{kg}^{-1}$ estimated fetal weight of $2 \mathrm{~kg}$ followed by a continuous infusion of 0.44 $\mathrm{mg} \cdot \mathrm{kg}^{-1} \cdot \mathrm{h}^{-1}$, a dose effective in reducing hypoxia-induced vasodilation in the rat hind $\operatorname{limb}(24,26)$. Hypoxia was administered for $30 \mathrm{~min}$ beginning one half hour after the start of the infusion by having the ewe breathe $10-12 \% \mathrm{O}_{2}$ in nitrogen administered with a flow rate of $30 \mathrm{~L} \cdot \mathrm{min}^{-1}$ into a bag placed over the ewe's head.

Blood sampling. Fetal arterial and sagittal sinus blood samples $(0.3 \mathrm{~mL}$ each) were collected at 0,15 , and 30 min during baseline period, at 40,50, and 60 min during the prehypoxia infusion period, at $65,70,80$, and 90 min during the infusion and hypoxia periods, at 100,110 , and 120 min during the posthypoxia infusion period, and at 135 and 150 min during the recovery period. These samples were analyzed for blood gases (ABL3, Radiometer, Copenhagen, Denmark), and values were corrected to the body temperature of the fetal sheep. Hemoglobin concentration and oxyhemoglobin saturation were measured spectrophotometrically (OSM2 Hemoximeter, Radiometer).

Plasma glucose and lactate concentrations were measured using an YSI 2700 analyzer (Yellow Springs Instruments, Dayton, OH). At 15 and 30 min during the baseline period, at 50 and 60 min during the prehypoxia infusion period, and at 65,80 , and 90 min during hypoxia period, additional fetal arterial blood samples $(0.7 \mathrm{~mL}$ each) were collected for prostanoid assay. The samples were centrifuged at $4^{\circ} \mathrm{C}$ for $5 \mathrm{~min}$ at $1000 \times \mathrm{g}$, and the plasma was removed and stored at $-70^{\circ} \mathrm{C}$. At a later date, the samples were thawed and pooled by animal and protocol stage, resulting in pooled arterial and sagittal sinus samples from the baseline, prehypoxia infusion, and the hypoxia periods for each animal studied. The pooled samples were analyzed via EIA by Cayman Chemical (Ann Arbor, MI) for $\mathrm{PGE}_{2}, \mathrm{PGI}_{2}$, and $\mathrm{TxA}_{2}$ concentrations. $\mathrm{PGE}_{2}$ concentrations were determined by conversion of all major $\mathrm{PGE}_{2}$ metabolites into a single stable derivative measurable via electroimmunoassay. $\mathrm{PGI}_{2}$ concentrations were determined by measurement of 6-keto-PGF $1 \alpha$ (a stable metabolite of $\mathrm{PGI}_{2}$ ). $\mathrm{TxA}_{2}$ concentrations were determined by measurement of $\mathrm{TxB}_{2}$ (a stable metabolite of $\mathrm{TxA}_{2}$ ).
Electronic data acquisition and handling. Measurements of local CBF were performed continuously with a laser Doppler flowmeter (Oxyflow, Oxford Optronix, Oxford, UK), whose results have been found in satisfactory agreement with microsphere determinations (27). Analogue outputs were digitized (sampling rate $100 \mathrm{~Hz}$ ) and stored using an analogue-to-digital converter (Powerlab 16/SP, ADInstruments, Colorado Springs, CO) and data acquisition software (Chart v.5, ADInstruments). Because laser Doppler flowmetry provides only a relative measure of blood flow, all values calculated using $\mathrm{CBF}$ are presented as a percentage change from baseline values. $\mathrm{CBF}$, cortical tissue $\mathrm{PO}_{2}$, arterial blood pressure corrected for amniotic fluid pressure, heart rate, and sagittal sinus pressure were calculated and expressed as 3-min averages. Cerebral vascular resistance was calculated as the difference between arterial and sagittal sinus pressure divided by CBF. Due to loss of sagittal sinus catheter patency, arterial blood pressure was assumed to be equivalent to cerebral perfusion pressure in four of the sheep studied under both the control and diclofenac protocols. Cerebral vascular resistance and mean arterial blood pressure were also expressed as a percentage of baseline measurements.

Western blotting. Previously unstudied near-term pregnant ewes whose vessels were to be used for other studies were killed with an overdose of pentobarbital. Fetal middle cerebral artery segments were collected for Western immunoblotting to determine COX-1 and COX-2 protein abundances. Total cellular proteins were obtained by glass-on-glass homogenization of the freshly frozen artery segments at a fixed buffer-to-tissue ratio of $60 \mu \mathrm{L} / \mathrm{mg}$ wet weight. The homogenization procedure (28) used a Laemmli buffer (0.125 mM TrisHCl, pH 6.8, containing $10 \%$ glycerol, $2.5 \%$ SDS, $0.006 \%$ bromophenol blue, and $0.1 \mathrm{M}$ dithiothreotol) followed by boiling for $10 \mathrm{~min}$ at $100^{\circ} \mathrm{C}$. Proteins $(30 \mu \mathrm{g}$ protein/lane) were separated by $10 \%$ sodium dodecylsulfate-polyacrylamide gel electrophoresis and transferred to nitrocellulose membranes. The membranes were blocked overnight with $5 \%$ milk in triethanolamine buffered saline and $0.1 \%$ Tween 20 . The membranes were probed for $2 \mathrm{~h}$ with COX-1 or COX-2 human monoclonal antibody (Cayman Systems, Stoneham, MA at 1:500 dilution), followed by a horseradish peroxidase goat anti-mouse IgG (HRP Pierce at 1:15,000 dilution). The immunoreactive bands were visualized using an AlphaInnotech ChemiImager and quantified by digital densitometry. Known amounts of human recombinant standards (Cayman Systems, Stoneham, MA) were included in each gel to prepare a standard curves from which the absolute masses of COX-1 and COX-2 were determined.

Statistical methods. Data are presented as means \pm the standard error of the mean (SEM) [standard error (SE)]. For statistical analysis of continuously measured parameters, mean values for each consecutive 15 -min period of the experiment were used. The significance of changes over time was evaluated using a one-way analysis of variance (ANOVA) with repeated measures and Dunnett's post hoc test when a significant difference was detected by ANOVA. The significance of differences between the control and diclofenac results was evaluated using a two-way ANOVA with a Bonferroni post hoc test. Comparison of COX-1 and COX-2 protein was performed using an unpaired $t$ test with Welch's correction. Graphpad Prism 3.0 (Graphpad Software Inc., San Diego, CA) was used for all statistical analyses.

\section{RESULTS}

Blood gases, pH, oxyhemoglobin saturation, glucose, and lactate values. Table 1 provides the results of fetal arterial blood gases, $\mathrm{pH}$, and plasma glucose and lactate values. The similar fall in arterial $\mathrm{Po}_{2}$ and oxygen content during the period of hypoxia indicates a comparable hypoxic stress in the two study groups. During hypoxia, arterial $\mathrm{Po}_{2}$ decreased 23 to 12 Torr, $\mathrm{PCO}_{2}$ decreased from 49 to 42 Torr (attributable to maternal hyperventilation), and a mild metabolic acidosis developed. Blood gas values returned to baseline levels during the hour following hypoxia.

Cortical Tissue $\boldsymbol{P o}_{2}$. Cortical tissue $\mathrm{Po}_{2}$ measurements are shown in Figure 1. Tissue $\mathrm{PO}_{2}$ decreased markedly from baseline values to comparable levels in both groups, again indicating a comparable level of hypoxic stress. During hypoxia, cortical tissue $\mathrm{Po}_{2}$ ranged from 2 to 3 Torr.

Cortical blood flow and vascular resistance. Figure 2 shows changes in cortical blood flow and cortical resistance to blood flow for the control and diclofenac experiments. In the 
Table 1. Arterial blood gases, oxygen content (O2 ct), pH, glucose (gluc), and lactate (lact) in response to drug infusion and hypoxia

\begin{tabular}{ccccc}
\hline & Baseline & Infusion & Hypoxia & Recovery \\
\hline $\mathrm{Po}_{2}$ (Torr) & & & & \\
Control & $22 \pm 1$ & $23 \pm 1$ & $12 \pm 1^{*}$ & $25 \pm 1^{*}$ \\
$\begin{array}{c}\text { Diclofenac } \\
\mathrm{O}_{2} \text { ct (mM) }\end{array}$ & $23 \pm 1$ & $22 \pm 1$ & $12 \pm 1^{*}$ & $24 \pm 1$ \\
$\quad$ Control & $7.1 \pm 0.2$ & $7.2 \pm 0.2$ & $3.2 \pm 0.1^{*}$ & $7.0 \pm 0.3$ \\
$\quad$ Diclofenac & $7.1 \pm 0.3$ & $7.1 \pm 0.2$ & $3.3 \pm 0.2^{*}$ & $6.7 \pm 0.3$ \\
$\mathrm{PcO}_{2}$ (Torr) & & & & \\
$\quad$ Control & $49 \pm 1$ & $49 \pm 1$ & $43 \pm 1^{*}$ & $48 \pm 2$ \\
Diclofenac & $50 \pm 1$ & $50 \pm 1$ & $43 \pm 1$ & $51 \pm 1$ \\
$\mathrm{pH}$ & & & & \\
Control & $7.34 \pm 0.01$ & $7.34 \pm 0.01$ & $7.35 \pm 0.01$ & $7.24 \pm 0.2^{*}$ \\
Diclofenac & $7.34 \pm 0.01$ & $7.33 \pm 0.01$ & $7.34 \pm 0.01$ & $7.22 \pm 0.0^{*}$ \\
Gluc (mM) & & & & \\
Control & $1.0 \pm 0.1$ & $1.0 \pm 0.1$ & $1.1 \pm 0.1$ & $1.3 \pm 0.1^{*}$ \\
Diclofenac & $1.1 \pm 0.1$ & $1.1 \pm 0.1$ & $1.3 \pm 0.1^{*}$ & $1.6 \pm 0.1^{*}$ \\
Lact (mM) & $1.0 \pm 0.1$ & $1.0 \pm 0.1$ & $2.7 \pm 0.2^{*}$ & $4.7 \pm 0.4^{*}$ \\
$\quad$ Control & & & & \\
Diclofenac & $1.0 \pm 0.1$ & $1.1 \pm 0.1$ & $3.0 \pm 0.2^{*}$ & $5.4 \pm 0.4^{*}$ \\
\hline
\end{tabular}

All values expressed as mean \pm SEM.

* Significant difference from baseline $(p>0.01)$.

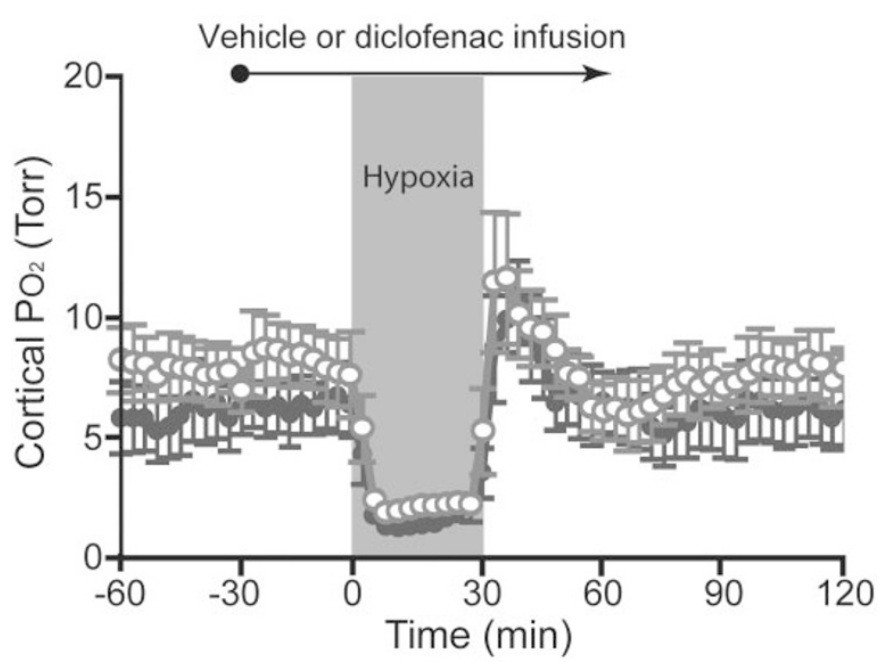

Figure 1. Cerebral cortical tissue $\mathrm{Po}_{2}$ levels during baseline, hypoxia, and recovery periods in control $(n=9)$ and diclofenac $(n=7)$ experiments.

control experiments, cortical blood flow increased progressively during the first $20 \mathrm{~min}$ of hypoxia, reaching a peak of $148 \pm 5 \%$ of baseline values at the end of the hypoxic period, a value significantly greater than baseline $(p<0.01)$. Flow returned to baseline values within $15 \mathrm{~min}$ after the end of hypoxia and remained stable during the remainder of the experiment. During hypoxia, resistance to flow decreased rapidly, reaching a nadir of $73 \pm 2 \%$ of baseline during the final $10 \mathrm{~min}$ of hypoxia. After the termination of hypoxia, resistance gradually increased to a peak of $137 \pm 10 \%$ of baseline, then gradually came back to baseline and remained stable during the recovery period.

When diclofenac was infused during the prehypoxic period, cortical blood flow did not change measurably. After induction of hypoxia, cortical blood flow increased significantly from baseline to reach a peak of $129 \pm 5 \%$. This increase was significantly less than that of the control group. CBF remained

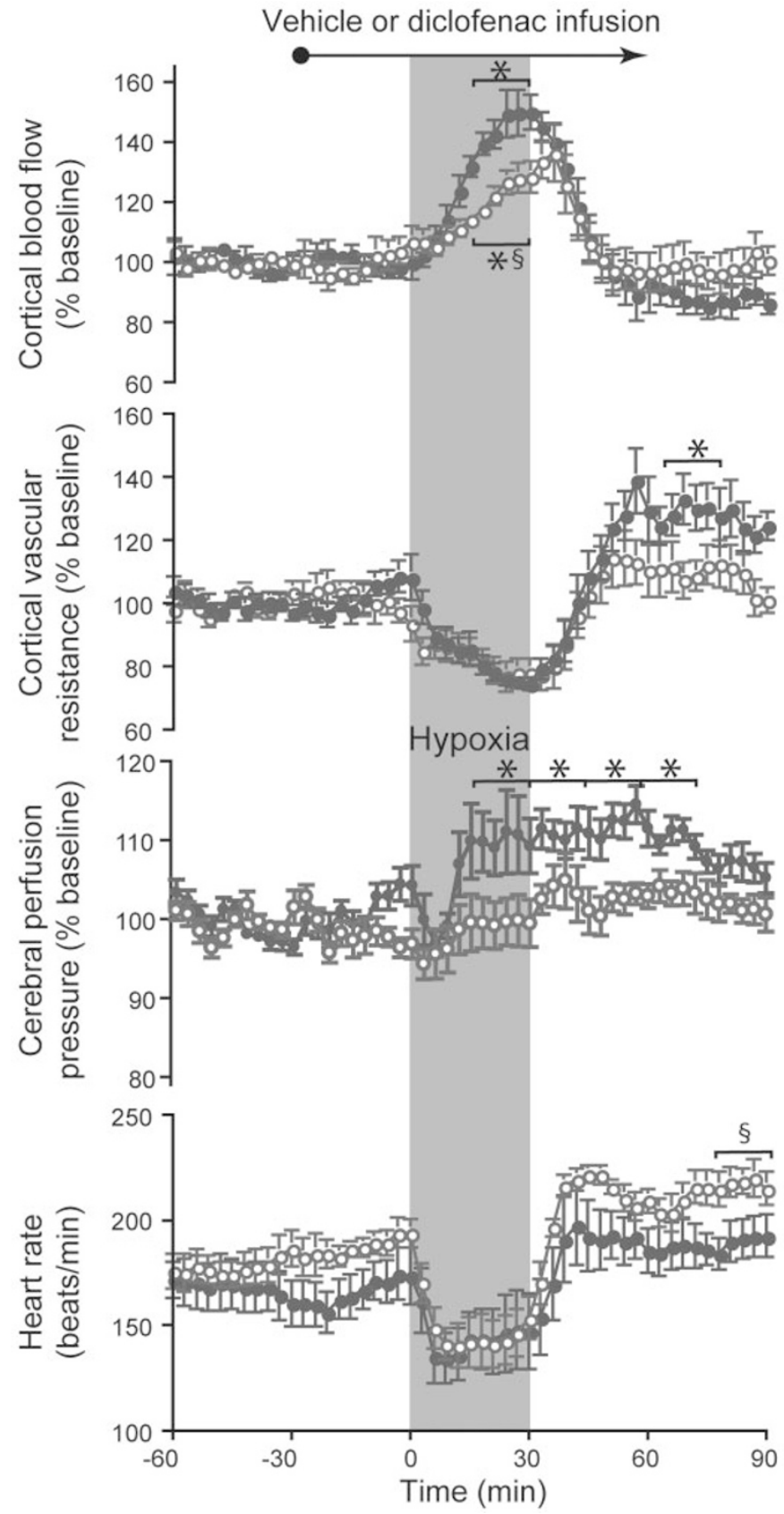

Figure 2. Changes in CBF, cerebral vascular resistance, mean arterial blood pressure, and heart rate during baseline, hypoxia, and recovery periods in control and diclofenac groups. Effect of hypoxia on CBF \pm SEM measured by laser Doppler flowmetry and cortical vascular resistance \pm SEM during the whole experiment in control $(n=8)$ and diclofenac $(n=7)$ groups. Effect of hypoxia on mean arterial blood pressure \pm SEM and heart rate \pm SEM during the whole experiment in control $(n=9)$ and diclofenac $(n=8)$ groups. $\S$ Significant difference between control and diclofenac $(p<0.01)$. *Significant difference from baseline period $(p<0.01)$. Two-way ANOVA revealed a significant difference between control and diclofenac experiments $(p<$ 0.01 ), although posttest did not identify a significant difference between treatments for any specific 15-min segment of the experiment.

elevated during the first $5 \mathrm{~min}$ of recovery from hypoxia and then gradually returned to baseline values for the remainder of the experiment. There were no significant differences in cerebral vascular resistance to blood flow between the control and diclofenac groups at any point during the study. 
A.

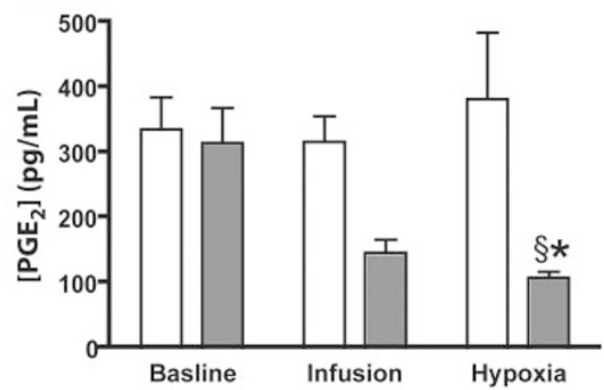

B.

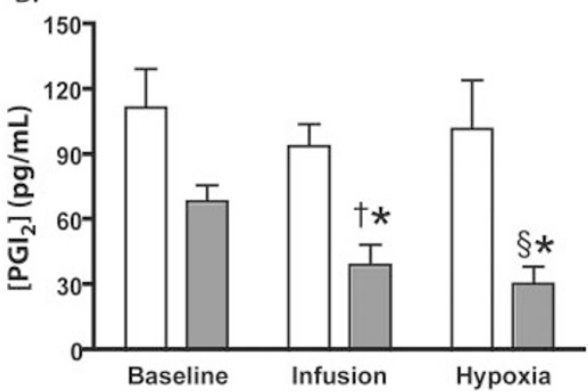

C.

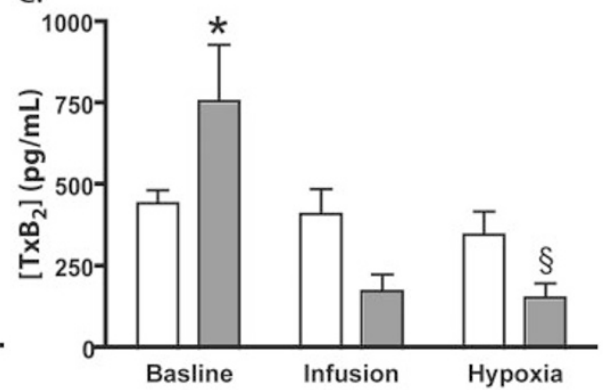

Figure 3. Arterial prostanoid concentrations during baseline, prehypoxia infusion (infusion), and hypoxia + infusion (hypoxia) periods in control (open columns) and diclofenac groups (solid columns). (A) Changes in arterial $\mathrm{PGE}_{2}$ content $(n=5)$. (B) Changes in arterial 6-keto $\mathrm{F}_{1} \alpha\left(\mathrm{PGI}_{2}\right)$ content $(n=5)$. $(C)$ Changes in arterial $\mathrm{TxB}_{2}\left(\mathrm{TxA}_{2}\right)$ content $(n=4)$. Treatment has a significant effect on all three metabolites $(p<0.01)$. Post hoc analyses are indicated by $\dagger$ (significant difference from controls) $(p<0.05)$, §significant difference from controls $(p<0.01)$, and $*$ significant difference from baseline $(p<0.01)$.

Mean arterial blood pressure and heart rate. Figure 2 shows mean arterial blood pressure and heart rate for both experimental groups. In control experiments, mean arterial blood pressure increased significantly from baseline values during the hypoxic period and did not return to baseline until approximately $45 \mathrm{~min}$ after the end of the hypoxic insult. In contrast, there were no significant changes in mean arterial blood pressure during hypoxia following diclofenac infusion. Two-way ANOVA detected a significant difference between control and diclofenac blood pressures, although the posttest did not find significance for any 15-min segment of the experiment. Other than a significant increase in heart rate during the last $15 \mathrm{~min}$ of the diclofenac experiments compared with baseline values, there were no significant changes in the diclofenac results compared with baseline or controls.

Plasma PGE, $\boldsymbol{P G I}_{2}$, and $\mathrm{TxA}_{2}$ values. Plasma concentrations of $\mathrm{PGE}_{2}, \mathrm{PGI}_{2}$, and $\mathrm{TxA}_{2}$ were measured to determine the effect of hypoxia on prostanoid synthesis and to establish the effectiveness of diclofenac blockade of prostanoid synthesis. The results are shown in Figure 3. In the control group, there were no significant changes in arterial $\mathrm{PGE}_{2}, \mathrm{PGI}_{2}$, or $\mathrm{TxA}_{2}$ throughout the course of the experiment. During the prehypoxic period in diclofenac experiments, $\mathrm{PGE}_{2}, \mathrm{PGI}_{2}$, and $\mathrm{TxA}_{2}$ all decreased, but the change only reached significance for $\mathrm{PGI}_{2}$. By completion of the hypoxic insult, the arterial concentrations of all three analytes had decreased measurably in diclofenac experiments despite large interanimal variability in absolute concentrations.

COX-1 and COX-2 concentrations in fetal middle cerebral arteries. To establish the presence or absence of COX-1 and COX-2 enzymes in the cerebral vasculature, Western blot analyses were conducted on middle cerebral arteries of fetal sheep. The results are shown in Figure 4. COX-1 was detected at a concentration of $0.05 \pm 0.004 \mu \mathrm{g} / \mu \mathrm{L}$, whereas COX-2 was found at a concentration of $0.15 \pm 0.029 \mu \mathrm{g} / \mu \mathrm{L}$. It may be noted that each microliter of the COX sample represented an equivalent wet weight mass of artery tissue (60 $\mu \mathrm{L}$ buffer per milligram of wet weight).

\section{DISCUSSION}

This study has shown that blockade of prostanoid synthesis by diclofenac attenuates the normal increase in cortical blood flow that occurs in response to hypoxia in near term fetal sheep. This attenuation occurred despite no measurable effect of diclofenac on cortical resistance to blood flow. These results indicate that, although prostanoids may play a systemic role in changes in blood flow distribution during hypoxia, they do not appear to act locally on resistance vessels in the brain. This conclusion is in accord with that reached earlier using the pial window technique in newborn piglets (16).

The prostanoids are produced by cyclization and then oxygenation of arachidonic acid to $\mathrm{PGH}_{2}$ (prostaglandin $\mathrm{H}_{2}$ ) by the COX-1 and COX-2 enzymes. $\mathrm{PGH}_{2}$ is subsequently converted to $\mathrm{PGE}_{2}, \mathrm{TxA}_{2}, \mathrm{PGI}_{2}, \mathrm{PGD}_{2}$ (prostaglandin $\mathrm{D}_{2}$ ), or $\mathrm{PGF}_{2 \alpha}$ by one of five different enzymes. Diclofenac has been shown to inhibit COX activity by competing with arachidonic acid for the active site (8). Unlike many COX inhibitors that exhibit greater inhibition of either COX-1 or COX-2, diclofenac is a relatively equipotent COX-1 and COX-2 inhibitor $(8,9)$. In addition, diclofenac has been reported to be effective in blockade of sheep COX enzymes and has fewer known nonspecific effects compared with many other COX inhibitors such as indomethacin (9).

Prostanoids are potent regulators of vascular tone, their effects being mediated by activation of $\mathrm{G}$ protein-coupled receptors on the plasma membrane (8,29). $\mathrm{PGE}_{2}, \mathrm{PGI}_{2}, \mathrm{TxA}_{2}$, and $\mathrm{PGF}_{2 \alpha}$ are known to be vasoactive in the fetal brain (22). In the present study, arterial plasma concentrations of $\mathrm{PGE}_{2}$ and 6-keto- $\mathrm{PGF}_{1 \alpha}$ (a stable metabolite of $\mathrm{PGI}_{2}$ ) were measured as known potent vasodilators $(15,30,31)$. $\mathrm{TxB}_{2}$ (a stable

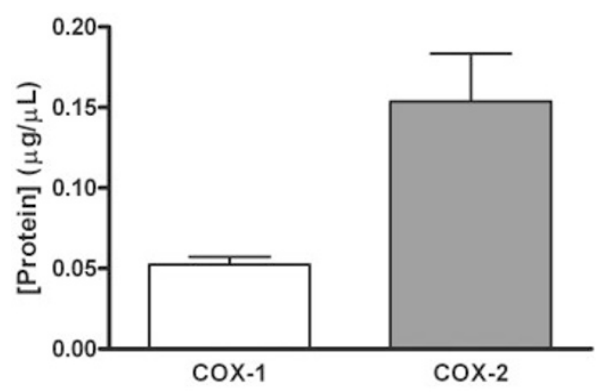

Figure 4. Middle cerebral artery concentrations of COX-1 and COX-2 as determined by Western blot analysis. Absolute COX-1 and COX-2 mass was determined based on a standard curve of mass vs. optical density for known amounts of human recombinant COX-1 and COX-2. 
metabolite of $\mathrm{TxA}_{2}$ ) was measured as a known potent vasoconstrictor $(16,32,33)$. Although hypoxia may induce tissuespecific changes in prostanoid production, arterial plasma concentrations of $\mathrm{PGE}_{2}, 6$-keto-PGF $\mathrm{PG}_{1 \alpha}$, and $\mathrm{TxB}_{2}$ were not affected by hypoxia in this study, a finding consistent with previous reports $(15,23)$. The magnitude of reductions in plasma concentrations of $\mathrm{PGE}_{2}, 6$-keto- $\mathrm{PGF}_{1 \alpha}$, and $\mathrm{TxB}_{2}$ following diclofenac infusion were also similar to those observed in previous reports in which COX inhibitors were systemically infused, most of which reported significant physiologic effects $(22,34,35)$.

Nonsteroidal antiflammatory drugs such as diclofenac and indomethacin have been shown to selectively antagonize COX enzymes (9). In adults and newborns, indomethacin, for example, has either no effect (36) or an attenuation of increased CBF in response to hypoxia (37). In the present study, increases in $\mathrm{CBF}$ were significantly attenuated, with no significant difference in cerebral resistance to flow between diclofenac and control experiments. Because arterial blood pressure was significantly lower in the diclofenac group compared with controls, the data suggest that the attenuation of increased CBF by diclofenac was related to systemic effects rather than direct effects on the cerebral vasculature. Thus, diclofenac results suggest that prostanoids do not bring about significant changes in cerebrovascular tone during hypoxia, although the prostanoids may be important in mediating systemic responses to hypoxia, which in turn indirectly alter cortical blood flow in the fetus $(1,7)$.

Although the results of the present studies indicate that prostanoids are not necessary for regulation of fetal cerebral vascular tone during hypoxia, Western blotting data indicate that both $\mathrm{COX}-1$ and $\mathrm{COX}-2$ are indeed present in the cerebral vasculature. The finding that $\mathrm{COX}-2$ concentrations were appreciably higher than those of COX-1 may represent a significant difference between the fetus and adult, as Schonbeck et al. (38) have reported COX-1 but undetectable levels of COX-2 in normal adult human vascular smooth muscle, whereas Parfenova et al. (28) have measured constitutive expression of both COX-1 and COX-2 in the newborn. The potency of diclofenac against $\mathrm{COX}-1$ is nearly equivalent to that of COX-2 in the sheep (9). It is worth noting that quantification of COX enzymes in these experiments was performed using sheep tissues but human recombinant protein standards. In addition, the quantification of $\mathrm{COX}$ protein concentrations does not provide an accurate indication of enzyme activity in vivo. Thus, although these findings indicate that COX enzymes are present in fetal cerebral vasculature, because of differences across species and age, the relative physiologic contributions of the two enzymes cannot be determined from the present experiments. There also remains the possibility that vascular tone did not change because of a balanced reduction of vasoconstrictor and vasodilator prostanoids by diclofenac administration.

In recent years our work has focused on the mechanisms regulating fetal $\mathrm{CBF}$ during hypoxia. We have established a predominant role for adenosine $(2,6)$, a lesser role for nitric oxide (5), and now a limited and largely systemic role for the prostanoids. It is likely that these mediators and others such as carbon monoxide (39) interact and compensate for one another in a complex and redundant system to mediate responses to hypoxia. Indeed, there are many reports of a variety of mediators stimulating production or activity of one or more others $(24,25)$.

In summary, administration of diclofenac does not affect cortical blood flow during a normoxic baseline period, but rather attenuates the normal increases in cortical blood flow that occur in response to hypoxic. The attenuation is not brought about locally, but rather by peripheral actions, perhaps principally by reductions in blood pressure, cardiac function and by inducing changes in other mediators.

\section{REFERENCES}

1. Jensen A, Garnier Y, Berger R 1999 Dynamics of fetal circulatory responses to hypoxia and asphyxia. Eur J Obstet Gynecol Reprod Biol 84:155-172

2. Blood AB, Hunter CJ, Power GG 2002 The role of adenosine in regulation of cerebral blood flow during hypoxia in the near-term fetal sheep. J Physiol 543:10151023

3. Ashwal S, Dale PS, Longo LD 1984 Regional cerebral blood flow: studies in the fetal lamb during hypoxia, hypercapnia, acidosis, and hypotension. Pediatr Res 18:1309-1316

4. Hunter CJ, Blood AB, Power GG 2003 Cerebral metabolism during cord occlusion and hypoxia in the fetal sheep: a novel method of continuous measurement based on heat production. J Physiol 552:241-251

5. Hunter CJ, Blood AB, White CR, Pearce WJ, Power GG 2003 Role of nitric oxide in hypoxic cerebral vasodilatation in the ovine fetus. J Physiol 549:625-633

6. Blood AB, Hunter CJ, Power GG 2003 Adenosine mediates decreased cerebral metabolic rate and increased cerebral blood flow during acute moderate hypoxia in the near-term fetal sheep. J Physiol 553:935-945

7. Reuss ML, Parer JT, Harris JL, Krueger TR 1982 Hemodynamic effects of alphaadrenergic blockade during hypoxia in fetal sheep. Am J Obstet Gynecol 142:410 415

8. Simmons DL, Botting RM, Hla T 2004 Cyclooxygenase isozymes: the biology of prostaglandin synthesis and inhibition. Pharmacol Rev 56:387-437

9. Mitchell JA, Akarasereenont P, Thiemermann C, Flower RJ, Vane JR 1993 Selectivity of nonsteroidal antiinflammatory drugs as inhibitors of constitutive and inducible cyclooxygenase. Proc Natl Acad Sci U S A 90:11693-11697

10. Pickles H, Brown MM, Thomas M, Hewazy AH, Redmond S, Zilkha E, Marshall J 1984 Effect of indomethacin on cerebral blood flow, carbon dioxide reactivity and the response to epoprostenol (prostacyclin) infusion in man. J Neurol Neurosurg Psychiatry 47:51-55

11. Schumann P, Touzani O, Young AR, Verard L, Morello R, MacKenzie ET 1996 Effects of indomethacin on cerebral blood flow and oxygen metabolism: a positron emission tomographic investigation in the anaesthetized baboon. Neurosci Lett 220:137-141

12. Wang Q, Paulson OB, Lassen NA 1993 Indomethacin abolishes cerebral blood flow increase in response to acetazolamide-induced extracellular acidosis: a mechanism for its effect on hypercapnia? J Cereb Blood Flow Metab 13:724-727

13. Niwa K, Haensel C, Ross ME, Iadecola C 2001 Cyclooxygenase-1 participates in selected vasodilator responses of the cerebral circulation. Circ Res 88:600-608

14. Chemtob S, Laudignon N, Beharry K, Rex J, Varma D, Wolfe L, Aranda JV 1990 Effects of prostaglandins and indomethacin on cerebral blood flow and cerebral oxygen consumption of conscious newborn piglets. Dev Pharmacol Ther 14:1-14

15. Coyle MG, Oh W, Petersson KH, Stonestreet BS 1995 Effects of indomethacin on brain blood flow, cerebral metabolism, and sagittal sinus prostanoids after hypoxia. Am J Physiol 269:H1450-H1459

16. Leffler CW, Parfenova H 1997 Cerebral arteriolar dilation to hypoxia: role of prostanoids. Am J Physiol 272:H418-H424

17. Hohimer AR, Richardson BS, Bissonnette JM, Machida CM 1985 The effect of indomethacin on breathing movements and cerebral blood flow and metabolism in the fetal sheep. J Dev Physiol 7:217-228

18. Van Bel F, Bartelds B, Teitel DF, Rudolph AM 1995 Effect of indomethacin on cerebral blood flow and oxygenation in the normal and ventilated fetal lamb. Pediatr Res 38:243-250

19. Markus HS, Vallance P, Brown MM 1994 Differential effect of three cyclooxygenase inhibitors on human cerebral blood flow velocity and carbon dioxide reactivity. Stroke 25:1760-1764

20. McCalden TA, Nath RG, Thiele K 1984 The role of prostacyclin in the hypercapnic and hypoxic cerebrovascular dilations. Life Sci 34:1801-1807

21. Juranek I, Bauer V, Donnerer J, Lembeck F, Peskar BA 2002 Severe hypoxia inhibits prostaglandin $\mathrm{I}(2)$ biosynthesis and vasodilatory responses induced by ionophore A23187 in the isolated rabbit ear. Pharmacology 66:199-205

22. Tong H, Wood CE 1999 Indomethacin attenuates the cerebral blood flow response to hypotension in late-gestation fetal sheep. Am J Physiol 277:R1268-R1273

23. Hooper SB, Harding R, Deayton J, Thorburn GD 1992 Role of prostaglandins in the metabolic responses of the fetus to hypoxia. Am J Obstet Gynecol 166:1568-1575

24. Marshall JM 2000 Adenosine and muscle vasodilatation in acute systemic hypoxia Acta Physiol Scand 168:561-573 
25. Salvemini D 1997 Regulation of cyclooxygenase enzymes by nitric oxide. Cell Mol Life Sci 53:576-582

26. Ray CJ, Abbas MR, Coney AM, Marshall JM 2002 Interactions of adenosine, prostaglandins and nitric oxide in hypoxia-induced vasodilatation: in vivo and in vitro studies. J Physiol 544:195-209

27. Abran D, Varma DR, Li DY, Chemtob S 1994 Reduced responses of retinal vessels of the newborn pig to prostaglandins but not to thromboxane. Can J Physiol Pharmacol 72:168-173

28. Parfenova H, Eidson TH, Leffler CW 1997 Upregulation of COX-2 in cerebral microvascular endothelial cells by smooth muscle cell signals. Am J Physiol 273:C277-C288

29. Wright DH, Abran D, Bhattacharya M, Hou X, Bernier SG, Bouayad A, Fouron JC, Vazquez-Tello A, Beauchamp MH, Clyman RI, Peri K, Varma DR, Chemtob S 2001 Prostanoid receptors: ontogeny and implications in vascular physiology. Am J Physiol Regul Integr Comp Physiol 281:R1343-R1360

30. Leffler CW, Busija DW, Beasley DG 1987 Effect of therapeutic dose of indomethacin on the cerebral circulation of newborn pigs. Pediatr Res 21:188-192

31. Brian JE Jr, Moore SA, Faraci FM 1998 Expression and vascular effects of cyclooxygenase-2 in brain. Stroke 29:2600-2606

32. Abran D, Li DY, Varma DR, Chemtob S 1995 Characterization and ontogeny of PGE2 and PGF2 alpha receptors on the retinal vasculature of the pig. Prostaglandins 50:253-267
33. Hou X, Gobeil F Jr, Peri K, Speranza G, Marrache AM, Lachapelle P, Roberts J2nd, Varma DR, Chemtob S, Ellis EF 2000 Augmented vasoconstriction and thromboxane formation by $15-\mathrm{F}(2 \mathrm{t})$-isoprostane (8-iso-prostaglandin $\mathrm{F}(2 \mathrm{alpha})$ ) in immature pig periventricular brain microvessels. Stroke 31:516-524 discussion 525.

34. Adamson SL, Engelberts D, Whiteley KJ 1997 Low dose indomethacin via fetal vein or cerebral ventricle stimulates breathing movements in fetal sheep. Can J Physio Pharmacol 75:135-142

35. Najarian T, Marrache AM, Dumont I, Hardy P, Beauchamp MH, Hou X, Peri K, Gobeil F Jr, Varma DR, Chemtob S 2000 Prolonged hypercapnia-evoked cerebral hyperemia via $\mathrm{K}(+)$ channel- and prostaglandin $\mathrm{E}(2)$-dependent endothelial nitric oxide synthase induction. Circ Res 87:1149-1156

36. Sakabe T, Siesjo BK 1979 The effect of indomethacin on the blood flow-metabolism couple in the brain under normal, hypercapnic and hypoxic conditions. Acta Physiol Scand 107:283-284

37. Coyle MG, Oh W, Stonestreet BS 1993 Effects of indomethacin on brain blood flow and cerebral metabolism in hypoxic newborn piglets. Am J Physiol 264:H141-H149

38. Schonbeck U, Sukhova GK, Graber P, Coulter S, Libby P 1999 Augmented expression of cyclooxygenase-2 in human atherosclerotic lesions. Am J Pathol 155:1281-1291

39. Leffler CW, Fedinec AL, Parfenova H, Jaggar JH 2005 Permissive contributions of $\mathrm{NO}$ and prostacyclin in $\mathrm{CO}$-induced cerebrovascular dilation in piglets. Am J Physiol Heart Circ Physiol 289:H432-H438 